\title{
Processo de Desenvolvimento do jogo sério Missão Aedes: relações entre objetivos pedagógicos, ludicidade e implicações de design
}

\author{
Débora da Conceição Araújo ${ }^{1}$, Ariane Nunes Rodrigues ${ }^{1}$, Paulo Vinícius de L. \\ Lima $^{1}$, Máverick André D. Ferreira ${ }^{2}$, Higor Ricardo M. Santos ${ }^{1}$ \\ ${ }^{1}$ Universidade de Pernambuco, Campus Garanhuns (UPE) \\ CEP 55.294-902 - Garanhuns - PE - Brasil \\ ${ }^{2}$ Departamento de Estatística e Informática \\ Universidade Federal Rural de Pernambuco (UFRPE) - Recife, PE - Brasil \\ \{deeboraaraaujo,vinicius.spk, amaverick70\}gmail.com, \\ \{ariane.rodrigues, higor.monteiro\}upe.br
}

\begin{abstract}
The educational games aimed at primarily educational objectives, that is, your objective is to contribute to the learning of students. The low acceptance for this kind of software, when labeled as boring and not fun, reflects the development process oriented learning objectives only. The importance of making the "learn by playing" pleasurable and fun becomes a challenge that should be considered to promote alignment between the objectives and the playful elements. This article presents the process of developing an educational game for the context of combat against the Aedes Aegypt. In its conception, the learning objectives of the game reflect cognitive processes involved in interface design strategies, for to promote playfullness.
\end{abstract}

Resumo. Jogos educativos, também conhecidos por jogos sérios, visam à promoção da aprendizagem de forma lúdica. Porém, é recorrente esse tipo de software sofrer por baixa aceitação, quando tachados como chatos e não divertidos. Isso reflete um processo de desenvolvimento orientado apenas aos objetivos de aprendizagem. A importância de tornar o "aprender jogando" prazeroso e divertido torna-se um desafio que deve ser considerado para promover o alinhamento entre os objetivos do jogo e seus elementos lúdicos. Este artigo apresenta o processo de desenvolvimento de um jogo sério para o contexto de combate ao mosquito Aedes Aegypti. Em sua concepção, os objetivos de aprendizagem definidos refletem processos cognitivos implicados por estratégias de design na interface que visam promover a ludicidade.

\section{Introdução}

As Tecnologias de Informação e Comunicação (TIC) estão presentes em todos os níveis da sociedade, inclusive na Educação. Assim, diferentes recursos tecnológicos são adotados para facilitar a prática docente, além de melhorar a experiência dos alunos. Nesse sentido, [Gomes 2015] reforça que a contribuição dos dispositivos móveis para a educação não se trata de mais uma utopia técnica, e sim da real construção de novas 
V Congresso Brasileiro de Informática na Educação (CBIE 2016)

Anais do XXVII Simpósio Brasileiro de Informática na Educação (SBIE 2016)

práticas de ensino, principalmente ao considerar o perfil dos alunos atuais que, como nativos digitais, permanecem conectados boa parte do dia, e apresentam interesse em jogos.

A aprendizagem apoiada por jogos educativos é uma alternativa efetiva para esses alunos, pois são recursos que apoiam a prática didática e promovem engajamento e motivação ao processo de ensino e aprendizagem. O grande potencial dos jogos educativos está na possibilidade de despertar o interesse, além de propiciar a aprendizagem de conteúdos de diferentes áreas do conhecimento. Em definição, os jogos educativos, também conhecidos por jogos sérios, são tipos de softwares que visam primordialmente objetivos educacionais [Silva e Gomes 2015]. No entanto, mesmo que a aprendizagem seja o foco central deste recurso, o autor reforça a necessidade de promover o prazer e a diversão. Uma pesquisa realizada por [Clua e Bittencourt 2004] revela que $68 \%$ dos estudantes entrevistados consideraram ruins todos os jogos sérios que conheciam. Associa-se esse resultado ao fato de que promover a relação entre ludicidade e aprendizagem é um grande desafio durante a concepção de um jogo deste propósito.

Além deste, outros desafios também são enfrentados durante o processo de desenvolvimento de uma solução educativa. Devido ao grau de complexidade deste tipo de software, promover o alinhamento entre a equipe multidisciplinar torna-se essencial [Tchounikine 2011]. Neste sentido, [Ferreira e Rodrigues 2015] reforçam que o processo de desenvolvimento requer certos cuidados, além de dispor no software os conteúdos embasados por teorias de aprendizagem, deve-se enfatizar também as dimensões técnicas, especificamente a interface. É por meio da interface que os conteúdos são transmitidos e por isso ela possui parcela significativa na aprendizagem. Uma interface atraente, com dispositivos de interação adequados pode ter efeito positivo na usabilidade do software, em sua aceitação, bem como no seu potencial para promoção da aprendizagem [Reategui 2007]. Em jogos sérios, o ideal é considerar interfaces lúdicas de modo a contemplar implicações de design na interface, orientando o alcance aos processos cognitivos. Autores como [Nunes e Giraffa 2003], referem-se ao processo cognitivo humano como a forma que as pessoas processam informações, ou seja, como os seres humanos percebem, codificam, estocam, recuperam e utilizam as informações. Referenciados na área de Interação Humano Computador (IHC), os processos cognitivos podem assumir diferentes processos mentais (percepção; atenção; memória; aprendizagem; e leitura e fala) [Preece et al. 2005] que são ativados durante a interação com o jogo e, assim, podem promover formas efetivas na aprendizagem.

Ao considerar todo o contexto, este artigo apresenta o processo de desenvolvimento do Missão Aedes, um jogo sério referente a prevenção e combate ao mosquito Aedes Aegypti. Muito tem se falado em promover a conscientização e prevenção para evitar as doenças provenientes ao mosquito (dengue, febre amarela, chikungunya e zika vírus), desenvolver um jogo neste contexto requer pensar em estratégias conceituais alinhadas à interface para promover o atingimento dos objetivos pedagógicos sem perder a ludicidade. Neste sentido, este trabalho apresenta detalhes do jogo e do seu processo de desenvolvimento com ênfase nos objetivos pedagógicos, interface e promoção à aprendizagem dos conceitos. O jogo apresentado é resultado de um projeto realizado e promovido pela interdisciplinaridade das disciplinas de 
V Congresso Brasileiro de Informática na Educação (CBIE 2016)

Anais do XXVII Simpósio Brasileiro de Informática na Educação (SBIE 2016)

Engenharia de Software Educativo e Estágio III, desenvolvido por estudantes do curso de Licenciatura em Computação da Universidade de Pernambuco, campus Garanhuns.

\section{Referencial Teórico}

Segundo [Tchounikine 2011], o desenvolvimento de um software educativo pode ser guiado por etapas como imaginar, pensar e elaborar uma solução computacional baseada em objetivos pedagógicos. Associado a este fundamento, a etapa de imaginar, requer considerar o conceito do círculo mágico defendido por [Huizinga 2001] para pensar e elaborar todo o universo lúdico de um jogo. A Figura 1 representa a relação do universo real e experiências obtidas pela imersão no universo lúdico (círculo mágico), adaptada ao contexto do jogo Missão Aedes.

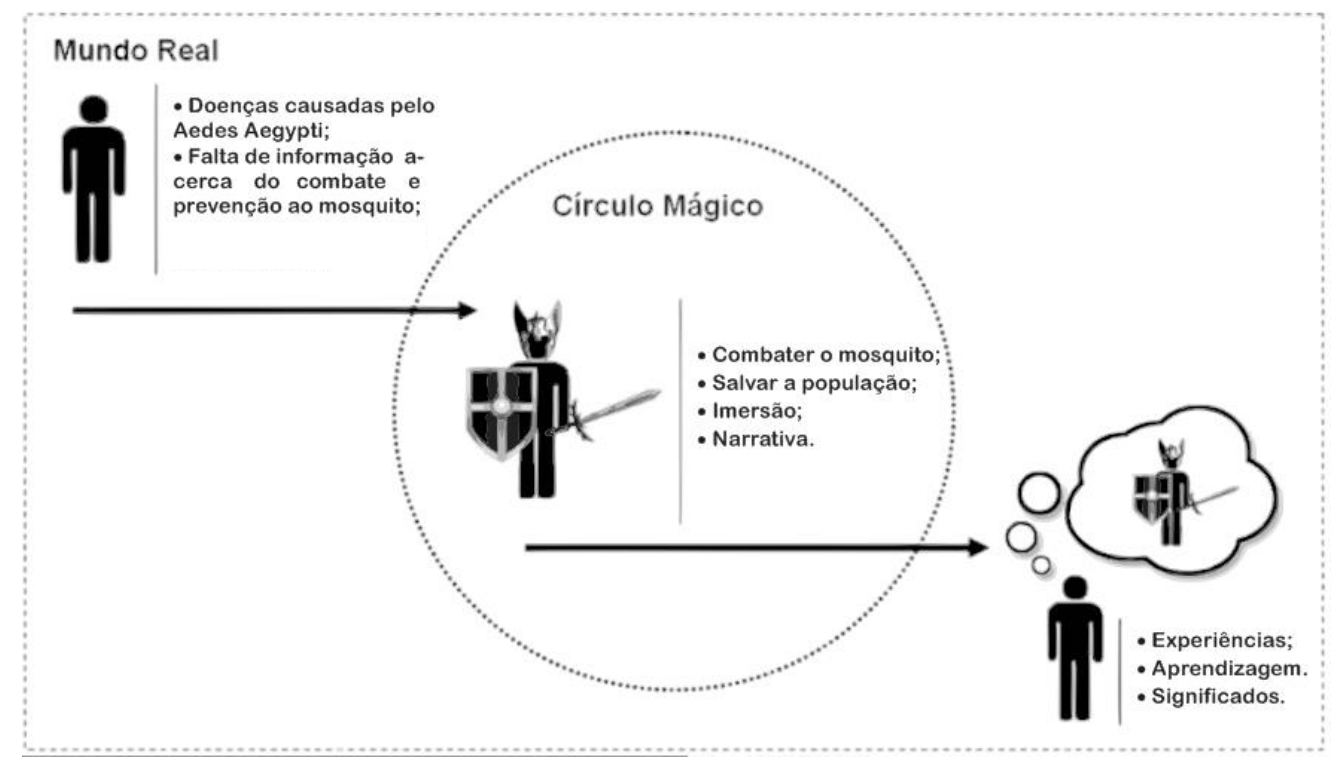

Figura 1. Círculo Mágico adaptado de [Mastrocola 2013] para o contexto do jogo.

Baseado nas definições de Huizinga, o círculo mágico é um universo lúdico paralelo ao cotidiano, onde as experiências realizadas dentro do círculo representam algo para aqueles que participam delas. Isso significa que ao imergir neste círculo, o indivíduo se envolve em experiências e significados que podem ser levados para sua vida. Ao considerar um jogo para o contexto atual, associado ao combate dos focos e epidemias promovidas pelo Aedes Aegipty, pode-se identificar no mundo real, através da representação da Figura 1, aspectos como as doenças causadas pelo mosquito e a falta de informação que, muitas vezes, leva as pessoas a assumir ações incoerentes quanto a prevenção e combate ao mosquito. No círculo mágico, ao imergir na narrativa do jogo, o aluno pode assumir o papel de heroi e, através de suas ações, destruir os mosquitos e salvar pessoas. Considerar que desafios com níveis de dificuldade gradativos promovem interesse e imersão ao mundo lúdico requer, durante a concepção do jogo, imaginar desafios relevantes ao contexto para que ao sair desse universo lúdico o aluno possa levar consigo aprendizagens, experiências e significados adquiridos. $\mathrm{O}$ ideal está na possibilidade de reforçar os significados atrelados ao combate ao mosquito e seus impactos para a sociedade, pois, acredita-se que com o jogo o aluno possa modificar seus hábitos, além de incentivar a mudança também aos seus familiares e amigos. 
V Congresso Brasileiro de Informática na Educação (CBIE 2016)

Anais do XXVII Simpósio Brasileiro de Informática na Educação (SBIE 2016)

Para elaborar um jogo sério avaliar soluções existentes também é uma estratégia interessante. Entender como o contexto do jogo foi definido, identificar aspectos positivos e negativos, além de promover a reflexão entre a equipe no processo de concepção. O jogo Contra a Dengue, por exemplo, permite que o aluno explore o ambiente e, ao passar por obstáculos, possa identificar e eliminar possíveis depósitos do mosquito [Pereira et al. 2011]. Já o Contra a Dengue $2^{1}$, como um jogo típico de memória, permite ao aluno identificar as figuras idênticas associadas ao contexto do mosquito.

Mesmo que a avaliação tenha um caráter pessoal e livre, é possível avaliar aspectos como qualidade das representações (conceitos), precisão das informações e adequação aos retornos. A percepção é que os jogos deste tema, mesmo definidos como educativos, apresentam uma fraca relação aos conteúdos. O lúdico não deveria vir associado apenas à ação de eliminar os mosquitos ou, para o caso do jogo da memória, apenas identificar as imagens idênticas. É preciso que o aluno entenda aspectos conceituais, como o próprio ciclo de vida do mosquito, por exemplo, para que o mesmo consiga identificar a relevância do conceito associado à razão (porquês) da prevenção e combate ao mosquito.

Neste sentido, os autores deste artigo, além de se basear na teoria do círculo mágico, também reforçam a importância de relacionar os objetivos de aprendizagem à ludicidade e aos processos cognitivos implicados por estratégias na interface. Assim, o artigo explora as relações existentes entre os objetivos pedagógicos, processos cognitivos e implicações de design como estratégia à ludicidade na concepção do jogo Missão Aedes, que será apresentado com detalhes na seção 4.

\section{Processo de Desenvolvimento}

Para o desenvolvimento do jogo foi considerado um ciclo de 5 etapas, conforme apresenta a Figura 2.

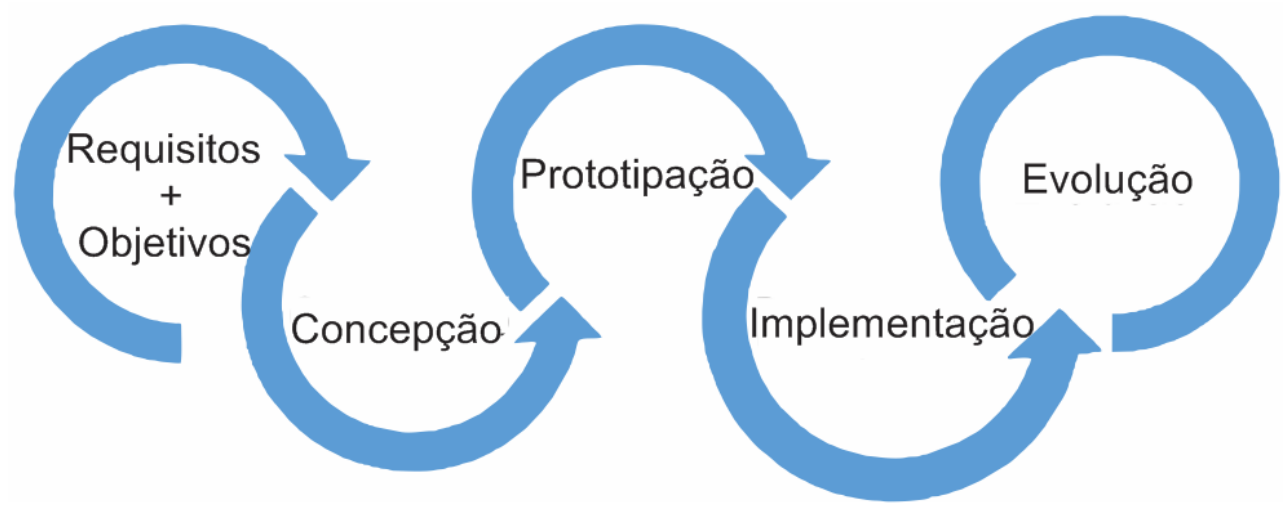

Figura 2. Etapas de Desenvolvimento do Missão Aedes

Na primeira etapa, um documento para elicitação dos requisitos foi elaborado para guiar o processo de desenvolvimento. De acordo com [Ramos et al. 2006], este documento é um artefato fundamental no processo de software, tendo em vista que a sua estrutura pode ser determinante na agilidade com que se consegue adaptar

\footnotetext{
${ }^{1}$ Disponível em http://portal.ludoeducativo.com.br/pt/play/jogo-da-memoria-contra-dengue-2
} 
V Congresso Brasileiro de Informática na Educação (CBIE 2016)

Anais do XXVII Simpósio Brasileiro de Informática na Educação (SBIE 2016)

eficazmente o software às mudanças de requisitos. Por se tratar de uma solução educativa, concomitantemente a definição dos requisitos, que representam as funcionalidades do jogo, os objetivos pedagógicos e de aprendizagem também foram estabelecidos. Para a definição dos objetivos de aprendizagem, o esquema classificatório da Taxonomia de Bloom Revisada [Anderson et al. 2001] foi adotado para combinar os processos cognitivos aos conteúdos e assim alinhar as estratégias implicadas na interface. A seção 5 apresenta detalhes mais específicos no que se refere a definição dos objetivos do jogo e sua relação com os processos cognitivos.

Durante a prototipação das telas do jogo, foi utilizada a versão de teste do software CorelDraw X7, por permitir criar telas mais próximas do resultado final, além de possibilitar a utilização das imagens posteriormente, durante a montagem do cenário e desenvolvimento do jogo. As interfaces foram definidas conforme as mecânicas estabelecidas e o processo evolutivo do jogo (melhorias eram sugeridas ao longo das disciplinas de Engenharia de Software Educativo e Estágio III). Para integrar o lúdico ao conteúdo presente nas interfaces, funções e efeitos foram estabelecidos para as imagens. A seção 6 apresenta detalhes mais específicos no que se refere as implicações de design do jogo.

Em relação a implementação, foi considerado o IDE Unity como plataforma de desenvolvimento licenciada para estudantes. Escolheu-se o Unity 5, pois o mesmo possibilita o desenvolvimento e exportação de jogos 2D para diversas plataformas, como Desktop, Mac, Android e WindowsPhone. Além disso, o Unity 5 suporta diversas linguagens de programação, facilitando o desenvolvimento dos scripts de acordo com a linguagem mais usada por cada programador da equipe.

\section{O jogo: Missão Aedes}

O Missão Aedes é um jogo de plataforma 2D, baseado em jogos clássicos como Sonic the Hedgehog e Super Mario World. Nestes jogos, o personagem explora as fases superando obstáculos e inimigos encontrados pelo caminho. A Figura 3 mostra a primeira fase do jogo.

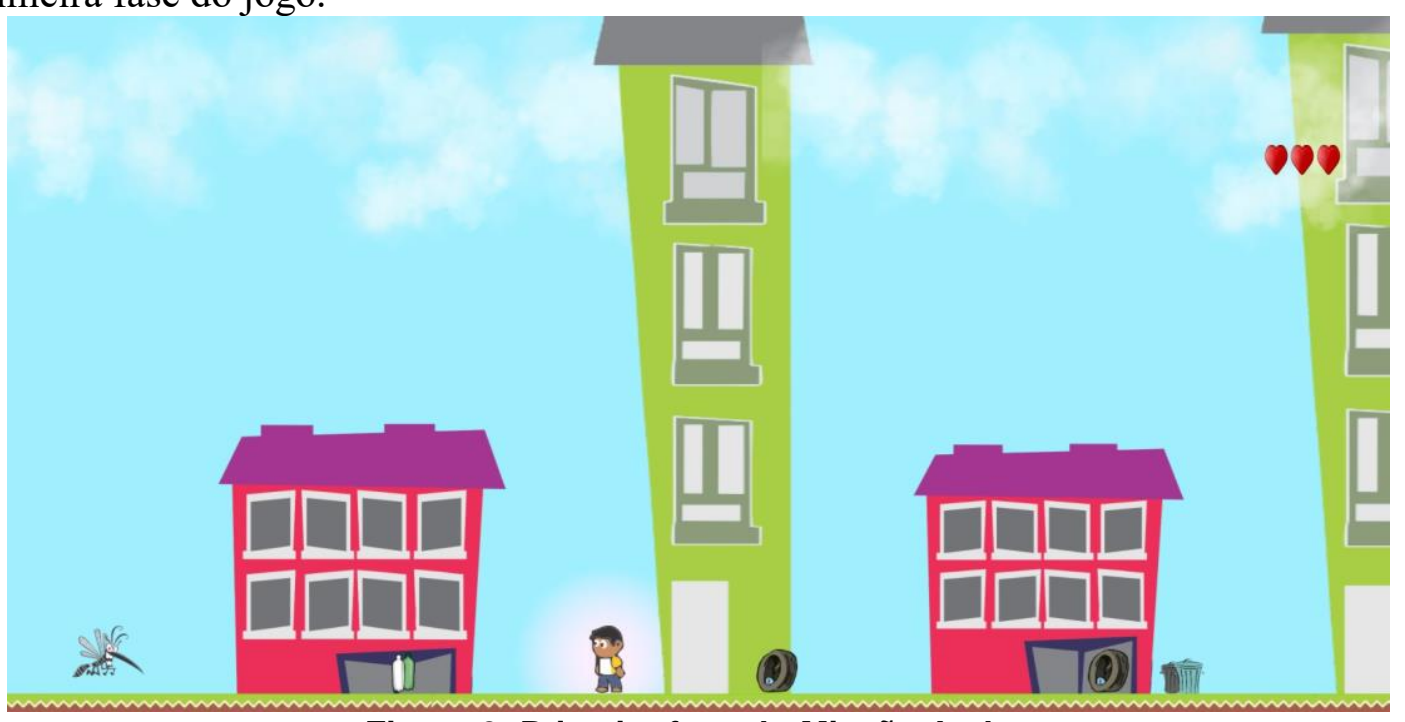

Figura 3. Primeira fase do Missão Aedes

O contexto do jogo reflete uma cidade repleta de focos e de mosquitos Aedes Aegypti. O personagem, representado por uma criança, precisa destruir os focos para 
V Congresso Brasileiro de Informática na Educação (CBIE 2016)

Anais do XXVII Simpósio Brasileiro de Informática na Educação (SBIE 2016)

impedir a proliferação do mosquito. A cada fase, o jogador precisa atingir determinadas metas em relação ao combate dos potenciais focos de proliferação. A Tabela 1 sintetiza as fases do jogo alinhadas aos objetivos do jogador e as metas que devem ser obtidas a cada fase.

Tabela 1. Definição das fases alinhadas a seus respectivos conteúdos

\begin{tabular}{|c|l|l|}
\hline $\begin{array}{c}\text { Fase } \\
\text { (F) }\end{array}$ & \multicolumn{1}{|c|}{ Objetivo do Jogador } & \multicolumn{1}{|c|}{ Metas a serem cumpridas a cada fase } \\
\hline $\begin{array}{c}\text { F1/ } \\
\text { F2 }\end{array}$ & $\begin{array}{l}\text { Reconheça e elimine os focos do } \\
\text { mosquito. }\end{array}$ & $\begin{array}{l}\text { Recolher pelo menos 10 objetos que são focos } \\
\text { do mosquito. }\end{array}$ \\
\hline F3 & $\begin{array}{l}\text { Entenda o ciclo de vida do } \\
\text { mosquito (Parte I). }\end{array}$ & $\begin{array}{l}\text { Selecione apenas os focos que representam o } \\
\text { mosquito em seu primeiro estágio de } \\
\text { desenvolvimento. }\end{array}$ \\
\hline F4 & $\begin{array}{l}\text { Perceba o quanto é importante } \\
\text { eliminar os focos do mosquito. }\end{array}$ & $\begin{array}{l}\text { Complete a fase em até 3 minutos antes que os } \\
\text { mosquitos entrem na fase adulta. Impeça que os } \\
\text { mosquitos se desenvolvam e infectem as } \\
\text { pessoas. }\end{array}$ \\
\hline F5 & $\begin{array}{l}\text { Entenda o ciclo de vida do } \\
\text { mosquito (Parte II). }\end{array}$ & $\begin{array}{l}\text { Selecione apenas os focos que representam o } \\
\text { mosquito em seu segundo estágio de } \\
\text { desenvolvimento. }\end{array}$ \\
\hline F6 & $\begin{array}{l}\text { Entenda o ciclo de vida do } \\
\text { mosquito (Parte III); e perceba o } \\
\text { quanto é importante eliminar os } \\
\text { focos do mosquito. }\end{array}$ & $\begin{array}{l}\text { Destrua todos os mosquitos em sua fase adulta, } \\
\text { dentro de 1 minuto. Elimine todos os mosquitos } \\
\text { para salvar a cidade. }\end{array}$ \\
\hline
\end{tabular}

De acordo com os objetivos das fases, cada foco recolhido é revertido em uma pontuação, que pode ser utilizada para comprar itens como inseticida e/ou repelente, que servem como itens de proteção. Com o repelente, por exemplo, o jogador não pode ser picado pelos mosquitos em sua fase adulta. $\mathrm{O}$ mosquito é o principal inimigo do personagem e a colisão permite que o jogador fique "doente", ou seja, perca vidas. Caso o personagem perca 3 vidas voltará para o início da fase e terá que percorrê-la novamente. Para que o personagem não seja picado, deve-se pular sobre o mosquito para matá-lo. Esta lógica é baseada nos jogos clássicos supracitados. Ao alcançar o objetivo da fase, o jogador é direcionado a uma porta para que avance às demais fases.

Entre as fases do jogo são apresentadas imagens explicando conteúdos (como as fases que compõem o ciclo de vida do mosquito) ou mostrando para a criança mudanças estruturais que estão ocorrendo na cidade e que impedem o desenvolvimento do mosquito. Na Tabela 1, percebe-se que todas as fases refletem objetivos associados a conteúdos que devem ser adquiridos. Como todo desenvolvimento de um jogo sério deve ser norteado pelos objetivos de aprendizagem, a próxima seção apresenta detalhes de como os objetivos de aprendizagem do jogo foram definidos, além de sua relação com o conteúdo e conhecimento.

\section{Objetivos Pedagógicos do Missão Aedes}

O objetivo central do jogo refere-se à promoção da conscientização quanto ao combate

e prevenção dos mosquitos Aedes Aegipty. A ideia do jogo é fomentar a 
responsabilidade dos indivíduos em combater os focos de proliferação do mosquito através de ações como o recolhimento dos focos que estão espalhados pela cidade.

Para alinhar o objetivo central aos aspectos de aprendizagem, objetivos de aprendizagem foram estabelecidos conforme a estrutura composta por verbos e substantivos definida em [Airasian e Miranda 2002; Ferraz e Belhot 2010]. Consideram-se objetivos de aprendizagem como descrições acerca de habilidades cognitivas atreladas a conteúdos que podem ser adquiridas através da interação com o jogo. Os objetivos foram classificados conforme a Taxonomia de Bloom Revisada [Anderson et al. 2001] que relaciona processos cognitivos aos processos do conhecimento. No geral, os objetivos definem que tipos de processos cognitivos precisam ser ativados durante a interação para obter um conteúdo através de um processo específico do conhecimento. A Tabela 2 sintetiza os objetivos de aprendizagem do jogo, além da relação com a forma de obtenção do conteúdo (processos do conhecimento).

Tabela 2. Descrição dos objetivos de aprendizagem mapeados aos processos do conhecimento

\begin{tabular}{|c|l|c|}
\hline $\begin{array}{c}\text { Objetivo de } \\
\text { Aprendizagem } \\
\text { (OA) }\end{array}$ & \multicolumn{1}{|c|}{ Descrição } & $\begin{array}{c}\text { Processo do } \\
\text { Conhecimento }\end{array}$ \\
\hline OA1 & $\begin{array}{l}\text { Lembrar quais são os focos do mosquito } \\
\text { reconhecendo-os durante as fases do jogo. }\end{array}$ & Conceitual \\
\hline OA2 & $\begin{array}{l}\text { Entender e analisar o ciclo de vida do mosquito, } \\
\text { interpretando e diferenciando as características de } \\
\text { cada fase deste ciclo. }\end{array}$ & $\begin{array}{c}\text { Conceitual e } \\
\text { Procedural }\end{array}$ \\
\hline OA3 & $\begin{array}{l}\text { Aplicar os conhecimentos adquiridos referentes aos } \\
\text { focos do mosquito, executando-os durante as fases de } \\
\text { modo a recolher a quantidade de focos estipulada. }\end{array}$ & Procedural \\
\hline OA4 & $\begin{array}{l}\text { Avaliar o ciclo de desenvolvimento do mosquito, } \\
\text { checando os focos emergenciais. }\end{array}$ & Metacognitivo \\
\hline
\end{tabular}

Praticamente todos os processos da taxonomia são contemplados no Missão Aedes, apenas o processo criar não foi adotado, pois o mesmo remete ao ato de produzir algo novo, o que não é proporcionado durante à interação com o jogo. Na Tabela 2, a relação de cada processo cognitivo ao processo do conhecimento é estabelecida, a saber: o OA1 é mapeado ao nível conceitual, pois reforça a ideia de que os alunos precisam lembrar os focos do mosquito (garrafas, pneus, caixa d'água aberta) e reconhecer que através desses objetos o mosquito deposita suas larvas, podendo se desenvolver; o OA2, por sua vez, está mapeado tanto ao nível conceitual quando ao nível procedural, tendo em vista que além de entender o ciclo de vida do mosquito é necessário saber diferenciar as características de cada fase; o OA3 também foi mapeado ao nível procedural, pois, através da aplicação dos conhecimentos adquiridos ao decorrer do jogo, o aluno saberá reconhecer os focos, para assim, recolhê-los; por fim, o OA4 está mapeado ao nível metacognitivo que associa a necessidade do aluno pensar estrategicamente. É neste objetivo que deve ser considerado o conhecimento adquirido quanto ao ciclo de vida do mosquito. Os alunos precisam avaliar os focos que estão no nível avançado (em situação emergencial) associados a proliferação do mosquito. 
V Congresso Brasileiro de Informática na Educação (CBIE 2016)

Anais do XXVII Simpósio Brasileiro de Informática na Educação (SBIE 2016)

\section{Implicações de Design do jogo}

A interface do jogo foi implementada tendo como base os objetivos de aprendizagem que associam os processos cognitivos aos conteúdos. O processo lúdico associado ao alcance dos objetivos do jogo refere-se à adoção de implicações de design em suas interfaces. Neste sentido, os processos cognitivos considerados referem-se à atenção, percepção, memória e aprendizagem.

Segundo [Preece et al. 2005], a atenção pode ser ativada por meio de uma implicação de design que permite ao usuário selecionar objeto(s). A percepção está associada a como o usuário adquire informações do ambiente e por isso, as representações gráficas precisam ser claras e compreensíveis. A memória, por sua vez, implica em promover a recordação de diversos tipos de conhecimentos, permitindo ao usuário agir adequadamente. Por fim, o aprendizado se refere à usabilidade do sistema, ou seja, interfaces que incentivam a exploração ao mesmo tempo em que restringem algumas opções para guiar o usuário a realizar escolhas adequadas.

A Tabela 3 apresenta os processos cognitivos mapeados aos objetivos de aprendizagem, bem como as implicações de design adotadas para promover a ludicidade no jogo.

Tabela 3. OAs mapeados aos processos cognitivos e implicações de design.

\begin{tabular}{|c|c|c|}
\hline $\begin{array}{l}\text { Objetivos de } \\
\text { Aprendizagem }\end{array}$ & $\begin{array}{l}\text { Processos } \\
\text { Cognitivos }\end{array}$ & Implicações de Design \\
\hline OA1 & $\begin{array}{l}\text { Atenção, } \\
\text { Percepção e } \\
\text { Memória }\end{array}$ & $\begin{array}{l}\text { Sons são emitidos sempre que se pega um objeto foco do } \\
\text { mosquito; Signos que remetem aos focos no mundo real. }\end{array}$ \\
\hline OA2 & Percepção & $\begin{array}{l}\text { Uso de figuras representativas e organizacionais que } \\
\text { remetem as etapas do ciclo de vida do mosquito (ovo, } \\
\text { larva, pupa e mosquito); Uso de som que indica que } \\
\text { personagem foi picado pelo mosquito em sua fase adulta. }\end{array}$ \\
\hline OA3 & Atenção & $\begin{array}{l}\text { Mensagens de alerta aparecem caso o aluno não colete a } \\
\text { quantidade de focos estipulada. }\end{array}$ \\
\hline OA4 & $\begin{array}{l}\text { Percepção e } \\
\text { Memória }\end{array}$ & $\begin{array}{l}\text { Uso de imagens representativas e organizacionais que } \\
\text { demonstram em que fase do ciclo de vida está o mosquito. }\end{array}$ \\
\hline
\end{tabular}

De acordo com a Tabela 3, é possível associar as mudanças esperadas através dos objetivos de aprendizagem às estratégias consideradas no que se refere à interface. $\mathrm{O}$ uso de imagens representativas e/ou organizacionais adotadas no jogo tem sua relevância apresentada em [Reategui 2007]. O autor destaca que efeitos e funções agregam a intencionalidade das imagens e animações adotadas em softwares educativos. As imagens com função decorativa focam na parte estética, ou seja, não carregam nenhuma mensagem direta associada ao conteúdo do software. Uma imagem com função representativa, por sua vez, transmite um conceito representado graficamente. Imagens com função organizacional ilustram relações entre elementos que compõem determinado objeto ou processo. E, por fim, a função explanatória explica o funcionamento de um sistema dinâmico, considerando a variável tempo. Ao considerar tais definições no jogo, as imagens referentes aos focos do mosquito assumem a função representativa. As imagens referentes ao ciclo de vida do Aedes 
V Congresso Brasileiro de Informática na Educação (CBIE 2016)

Anais do XXVII Simpósio Brasileiro de Informática na Educação (SBIE 2016)

além de representativas também são definidas como organizacionais, a depender da forma como elas aparecem nas fases do jogo.

Vale ressaltar que o processo cognitivo aprendizado também foi considerado na concepção do Missão Aedes por meio de estratégias referentes à usabilidade do jogo. A Figura 4 mostra um Menu Inicial simples, com opções claras e imagens com signos intuitivos, como no caso do símbolo de volume.

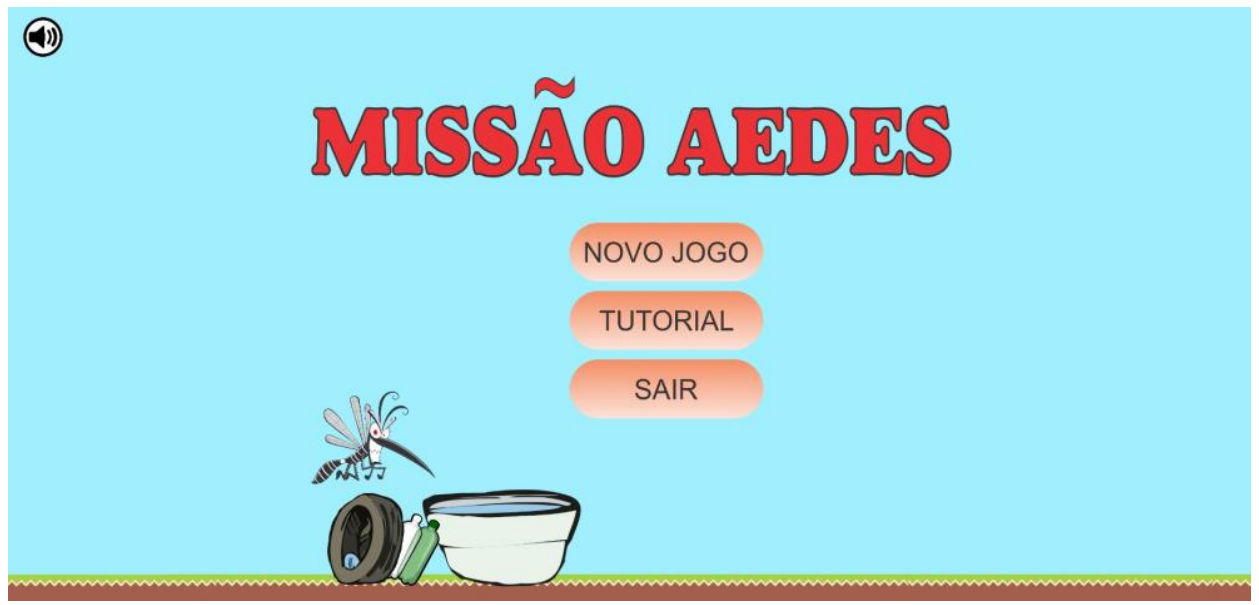

\section{Figura 4. Menu Inicial do jogo}

Assim, os elementos gráficos da interface, além de considerar aspectos de aprendizagem, adequam também estratégias de design que podem favorecer a ativação de processos cognitivos adequados a cada situação.

\section{Considerações Finais}

O presente artigo teve como objetivo relatar o processo de desenvolvimento do jogo sério Missão Aedes sob a perspectiva de relação entre os objetivos de aprendizagem, ludicidade e interface.

No processo de desenvolvimento do jogo foram considerados aspectos relacionados aos impactos que as implicações de design exercem em relação à ludicidade do jogo e ao atingimento dos objetivos pedagógicos. Para tal, processos cognitivos foram considerados, além de estratégias para promover a aprendizagem lúdica via interface.

Este artigo defende a necessidade de pensar e conceber jogos educativos que possam de fato promover a aprendizagem e que ao mesmo tempo sejam prazerosos, divertidos, lúdicos. Como trabalhos futuros espera-se realizar avaliações através da aplicação do jogo em parceria com escolas da rede pública de ensino para verificar seu impacto tanto na aprendizagem quanto na ludicidade que o mesmo promove.

\section{Referências}

Airasian, P. W.; Miranda, H. (2002). "The Role of Assessment in the Revised Taxonomy", In: Theory Into Practice, v. 41(4), p. 249-254.

Anderson, L. W.; Krasthwohl, D. R.; Airasian, P. W. (2001). "A taxonomy for learning, teaching and assessing: a revision of Bloom's Taxonomy of Educational Objectives". Nova York: Addison Wesley Longman. 
V Congresso Brasileiro de Informática na Educação (CBIE 2016)

Anais do XXVII Simpósio Brasileiro de Informática na Educação (SBIE 2016)

Clua, E. W. G.; Bittencourt, J. R. (2004). "Uma nova concepção para a criação de jogos educativos. In: XV Simpósio Brasileiro de Informática na Educação”. Manaus: Anais do Simpósio Brasileiro de Informática na Educação (SBIE), 2004.

Ferraz, A. P. do C. M.; Belhot, R. V. (2010). "Taxonomia de Bloom: revisão teórica e apresentação das adequações do instrumento para definição de objetivos instrucionais". Gest. Prod., São Carlos, v. 17, 2010.

Ferreira, M. A. D.; Rodrigues, A. N. (2015). "Interfaces Educativas: Implicações de design e processos cognitivos do jogo Nicetown", In: Congresso brasileiro de informática na educação - CBIE, 2015, Maceió - AL. Anais do XXVI Simpósio Brasileiro de Informática na Educação (SBIE 2015), 2015. p. 907-916.

Gomes, A. S. (2015). “A culpa é do celular?”. Disponível em: $<$ http://www.abble.com.br/a-culpa-e-do-celular/> Acesso em: Maio de 2016.

Huizinga, Johan. (2001). “Homo ludens”. São Paulo: Perspectiva, 2001.

Lakatos, M. E.; Marcone, M. de A. (2003). "Fundamentos de metodologia científica". São Paulo: Atlas 2003, $5^{\text {th }}$ edition.

Mastrocola, V. M. (2013). "Doses lúdicas: breves textos sobre o universo dos jogos e entretenimento". / Vicente Martin Mastrocola. - São Paulo: Independente, 2013.

Nunes, M., Girafa, L. (2003). “A educação na ecologia digital”. PPGCC/ FACIN, PUCRS.

Pereira, P. F.; Silva, R. B.; Bareato, R.; Camargo, T.; Bittar, T. J.; Longo, E. (2011). "Considerações para jogos de ação tipo plataforma com base as experiências do desenvolvimento do jogo Contra Dengue". In: X Simpósio Brasileiro de Jogos e Entretenimento Digital (SBGames), 2011, Salvador - BA. Anais do X Simpósio Brasileiro de Games e Entretenimento Digital (SBGames), 2011

Preece, J.; Rogers ,Y.; Sharp, H. (2005). "Design de Interação: Além da Interação Homem-Computador". Ed. Bookman, 2005.

Ramos, R. A.; Araújo, J.; Castro, J. F. B.; Moreira, A.; Alencar, F.; Silva, C. (2006). "Uma Abordagem de Instanciação de Métricas para Medir Documentos de Requisitos Orientados a Aspectos". In: $3^{\circ}$ Workshop Brasileiro de Desenvolvimento de Software Orientados a Aspectos - WASP2006, 2006, Florianópolis. anais do $3^{\circ}$ Workshop Brasileiro de Desenvolvimento de Software Orientados a Aspectos, 2006.

Reategui, E. (2007). "Interfaces para softwares educativos". Revista Novas Tecnologias na Educação (Renote), v.5, n.1, pág. 1-10.

Sampaio, I. A. (2006). “Aprendizagem Ativa em Sistemas de Filtragem Colaborativa”. Dissertação de Mestrado, Universidade Federal de Pernambuco.

Silva, Ana Cristina. B. da; Gomes, A. S. (2015) "Conheça e utilize software educativo: avaliação e planejamento para a educação básica”. Pipa Comunicação, 2015.

Tchounikine, P. (2011). "Computer Science and Educational Software Design: a resource for Multidisciplinary Work in Technology Enhanced Learning”, 2011. 